\title{
HOW I TREAT ELDERLY OR COMORBID PATIENTS WITH CHRONIC LYMPHOCYTIC LEUKEMIA
}

\begin{abstract}
Lukáš Smolej
Charles University in Prague, Faculty of Medicine and University Hospital Hradec Králové, Czech Republic: $2^{\text {nd }}$ Department of Medicine, Department of Hematology

Summary: Treatment of chronic lymphocytic leukemia (CLL) has recently undergone several major changes. Most importantly, large randomized trials (CLL-8 in first line and REACH in relapse) clearly demonstrated superiority of chemoimmunotherapy consisting of fludarabine, cyclophosphamide and rituximab (FCR) over fludarabine and cyclophosphamide (FC) alone, thus establishing FCR regimen as the new gold standard in younger and physically fit patients. However, management of elderly and/or comorbid patients is still a challenging task because they cannot be treated with agressive approaches due to high risk of unacceptable toxicity. To date, no randomized trials in this patient population have improved therapeutic results over chlorambucil; therefore, this agent remains the backbone of treatment against which the new protocols should be tested. When deciding about the intensity of treatment, performance status, biological age and number as well as severity of comorbidities should be taken into account. Emerging treatment concepts for elderly/comorbid patients include combination of chlorambucil with monoclonal antibodies (rituximab, ofatumumab, GA-101), fludarabine-based regimens in reduced doses or protocols based on bendamustine and lenalidomide. Combination of highdose steroids with rituximab represent a promising option in relapsed/refractory CLL; however, infectious toxicity remains a serious issue. Finally, ofatumumab monotherapy appears to be a safe and effective therapy for heavily pretreated patients with CLL. This article reviews the current and future possibilities in the treatment of elderly and comorbid patients with CLL.
\end{abstract}

Key words: Chronic lymphocytic leukemia; Comorbidity; Health-related quality of life; Creatinine clearance; Elderly patients; Low-dose fludarabine

\section{Introduction}

Chronic lymphocytic leukemia (CLL), the most common leukemic disorder in the Euro-American population $(12,35,39)$ is still considered incurable despite considerable progress in the recent years (allogeneic stem cell transplantation being the only potentialy curative treatment for a very small subgroup of highly selected patients). Chemoimmunotherapy, i.e. combination of monoclonal antibodies with chemotherapy, represents a major breakthrough in the management of CLL. Recently, two large randomized studies (German CLL-8 study in untreated patients and international REACH study in relapsed CLL) clearly demonstrated that addition of monoclonal anti-CD20 antibody rituximab to fludarabine and cyclophosphamide (FCR regimen) was associated with significantly higher overal response rate (ORR), complete remissions (CR) and longer progressionfree survival (PFS) $(30,47)$; moreover, patients treated with FCR in first line had significantly longer overall survival the first clinical study in the history of CLL treatment to achieve this endpoint. Therefore, FCR protocol is currently accepted as the gold standard in treatment of physically fit CLL patients. However, it is necessary to keep in mind that results of these studies are not applicable to patients of advance age and/or with serious comorbidities. It is a wellknown fact that clinical studies in CLL enroll mainly younger patients in a very good general condition. The median age of patients enrolled in the recent large randomized studies testing fludarabine-based regiments is between 58 and 64 years $(7,15,26,30,33,46-48$, Table 1$)$. In contrast, the median age at diagnosis of CLL is between 65 and 72 years and patients older than 65 years in fact account up to $50-75 \%$ of the CLL population $(11,12,35,39)$. Importantly, age has also been identified as one of crucial predictive factors for overall survival $(55,56)$. The field of elderly or comorbid patients with CLL has been somewhat neglected in the last 15-20 years as large trials concentrated mainly on younger and fitter patients able to tolerate intensive protocols (reviewed in 18). Therefore, it is not clear whether older/comorbid patients will also profit from newer treat- 
Tab. 1: Median age in recent randomized studies in CLL is considerable lower than in general CLL population. Median age in each randomization group.

\begin{tabular}{|l|c|c|c|c|}
\hline Author & Year & Design & Median age & Reference \\
\hline Rai & 2001 & $\begin{array}{c}\text { F vs CLB } \\
\text { vs F+CLB }\end{array}$ & $64 / 62 / 63$ & 46 \\
\hline Eichhorst & 2006 & FC vs F & $58 / 59$ & 15 \\
\hline Catovsky & 2007 & FC vs F & $64 / 65$ & 7 \\
\hline Flinn & 2007 & FC vs F & $61 / 61$ & 26 \\
\hline Knauf & 2009 & B vs CLB & $64 / 64$ & 33 \\
\hline Hallek & 2009 & FCR vs FC & $61 / 61$ & 30 \\
\hline Robak & 2010 & FCR vs FC & $62 / 63$ & 47 \\
\hline Robak & 2010 & FC vs CC & $59 / 58$ & 48 \\
\hline
\end{tabular}

F - fludarabine; CLB - chlorambucil; FC - fludarabine and cyclophosphamide; B - bendamustine; FCR - fludarabine, cyclophosphamide and rituximab; CC - cladribine and cyclophosphamide.

ment approaches such as purine analog combination regimens or chemoimmunotherapy (18). Retrospective analysis of data gathered by Barcelona group which showed that overall survival in patients older than 70 did not improve in the last decade in historical comparison to younger patients (1) does not support this hypothesis. Of course, definite answers can be provided by prospective randomized trials only.

\section{Specific issues in elderly/comorbid patients}

It has been demonstrated that organ functions deteriorate with advancing age. One of most important examples is renal function. Creatinine clearance has been reported to decrease at a rate of approximately $1 \%$ per year (34). Muscle mass and urinary creatinine excretion in advancing age decrease at similar rate; therefore, mean serum creatinine concentrations may stay nearly constant despite decreasing renal function. This may result in overestimation of renal function if serum creatinine alone is used to assess renal function and calculate drug dosages (reviewed in 34). These facts have obvious implications for the dosing of systemic treatment of elderly patients with CLL, especially fludarabine which is predominantly excreted via kidneys (43). For practical purposes, it is convenient (and common in CLL studies) to assess patients' renal function by calculated creatinine clearance formula developed by Cockroft and Gault (9). Indeed, an analysis of Cancer and Leukemia Group B (CALGB) study 9011 using fludarabine monotherapy in 192 previously untreated patients (median age, 64 years) found out that creatinine clearance below 80 $\mathrm{ml} / \mathrm{min}$. (but not age!) was predictive of higher toxicity (37). Comorbidities in general have detrimental effect on survival of cancer patients (42). A study specifically looking at the role of comorbidities in patients with malignant lymphomas reported shorter overall survival in patients with severe comorbidities (32). In contrast, a single-center analysis from Mayo Clinic identified age rather than comorbidities as significant factor for overall survival (55). However, this analysis was influenced by the fact that comorbidities were assessed at the time of CLL diagnosis, not at the time of treatment (which in many patients occurs several years after diagnosis and comorbidities may occur in the meantime). German CLL study group analyzed patients from two prospective trials. There was a trend towards shorter survival in comorbid patients (either with multiple comorbidities or with severe comorbid diseases); this was independent of age (10). As both age and comorbidities appear to play an important role in the prognosis of CLL patients, more prospective studies are clearly needed to shed more light on this topic.

\section{Therapeutic options for elderly/comorbid CLL patients}

\section{First-line treatment}

Chlorambucil, though an old drug first successfully used in CLL in 1950s (2), can be still regarded as gold standard in treatment of frail patients with CLL because no other regimens proved to be superior so far. There are several possible dosing schedules of chlorambucil: 1) low-dose approach using $0.1 \mathrm{mg} / \mathrm{kg}$ continuously, 2) pulse schedule of 0.4-0.8 $\mathrm{mg} / \mathrm{kg}$ every 2 weeks, used in German protocols (17), 3) $10 \mathrm{mg} / \mathrm{m}^{2}$ on days $1-7$ repeated every 28 days for up to 12 cycles, used in British studies (7), 4) $40 \mathrm{mg} / \mathrm{m}^{2}$ once monthly, used by Cancer and Leukemia Group B (CALGB) (46). As there have been no randomized trials comparing different chlorambucil schedules, identification of the best regimen is not possible. However, schedules using higher dose per cycle (German and British study groups) appear to be more effective. CLL-5 study conducted by German CLL Study Group has been so far the only randomized trial which specifically focused on elderly patients: comparison of fludarabine monotherapy to chlorambucil was performed in 193 untreated patients older than 65 years (median, 70 years). Although fludarabine induced significantly higher percentage of overall responses (ORR) and complete responses (CR) than chlorambucil (ORR, 72 vs. $51 \%, p=0.003$; CR, 7 vs $0 \%, p=0.011$ ), this did not translate into longer progression-free survival (median 19 vs 18 months, $\mathrm{p}=0.7$ ) and there was even a trend toward longer shorter overall survival in fludarabine-treated patients (fludarabine, median 46 months vs chlorambucil, 64 months, $p=0.15$ ). The results of PFS and OS could be in part attributed to the fact that significantly less patients in the fludarabine arm were retreated when disease progressed again ( 50 vs $77 \%$; $=0.006$ ) (17). Based on these results, the German CLL Study Group still considers chlorambucil as the standard treatment for elderly CLL patients. Results of CLL-5 study underline the fact that questions related to specific clinical settings (like treatment of patients with comorbidities) must be answered in a specifically de- 
signed clinical trials and it is not possible to simply extrapolate data from trials involving different patient population, i.e. younger and fitter patients. In contrast, subanalysis of British CLL4 trial (randomization between chlorambucil vs. fludarabine vs. fludarabine plus cyclophosphamide, FC) showed that FC combination fared better than chlorambucil with regard to ORR, CR and PFS in all subgroups including patients older than 70 years which comprised approximately $30 \%$ of study population. Overall survival was not significantly different. While FC caused more myelotoxicity, there was no significant increase in infections (7). However, this trial was not specifically designed for elderly patients.

\section{Treatment of relapse}

In general, patients may be retreated with the previously used regimen if they responded and the duration of response exceeded 12 months for conventional protocols like chlorambucil or fludarabine monotherapy or at least 24 months for fludarabine combinations (e.g., FC, FCR). Patients refractory to alkylator-based regimens and unsuitable for fludarabine may be treated by high-dose corticosteroids (see section Refractory disease).

\section{Dose-reduced protocols containing fludarabine}

Unacceptable myelotoxicity and/or infections represent the most important drawback in elderly/comorbid patients treated with intensive fludarabine-based chemo(immuno) therapy. Ferrajoli et al. reported results of FC and FCR regimens in 125 patients older than 70 years. Half of patients have been previously treated. Severe (CTC grade III/IV) myelotoxicity occured in 60 and $82 \%$; severe infections complicated treatment in 42 and $22 \%$, leading to early discontinuation in significant number of patients, especially in relapse - median number of administered cycles was only 2 for FC and 3 for FCR (22). Israeli Group on CLL reported results of fludarabine-based combination (monotherapy, FC or FC plus mitoxantrone) as salvage treatment in 82 CLL patients ( 32 older than 65 years with median age of $70)$. While ORR/CR was lower in older patients (59/0 \% vs $80 / 20 \%$ ), infectious toxicity in this subgroup was unacceptable: severe bacterial infections occured in $44 \%$ and neutropenic fever in $25 \%$, leading to at least one hospitalizazion due to infection in $63 \%$ of patients. Consequently, only $31 \%$ of patients completed the planned treatment (51).

Tab. 2: Results of studies using low-dose fludarabine-based regimens in the treatment of CLL and small lymphocytic lymphoma (SLL).

\begin{tabular}{|c|c|c|c|c|c|c|c|c|}
\hline Author, year & $\mathrm{n}$ & $\begin{array}{c}\text { Median age } \\
\text { (range) }\end{array}$ & $\begin{array}{c}\text { Pretreatment } \\
\text { status }\end{array}$ & Regimen & \begin{tabular}{|l|} 
ORR/ \\
CR(\%) \\
\end{tabular} & $\begin{array}{c}\text { Hematological } \\
\text { toxicity }\end{array}$ & $\begin{array}{c}\text { Other } \\
\text { toxicity }\end{array}$ & Ref. \\
\hline $\begin{array}{l}\text { Robertson, } \\
1995\end{array}$ & 80 & $66(43-79)$ & $\mathrm{Rel} / \mathrm{Ref}$ & $\begin{array}{l}\text { F } 30 \mathrm{mg} / \mathrm{m}^{2} \text { i.v. } \\
\text { D1-3 q28d }\end{array}$ & $41 / 10$ & $\begin{array}{l}\text { ANC gr. IV } \\
18 \% \text { courses }\end{array}$ & $\begin{array}{c}\text { 19x pneumonia, } \\
13 x F U O\end{array}$ & 49 \\
\hline $\begin{array}{l}\text { Bocchia, } \\
1999\end{array}$ & $30 *$ & $68(32-82)$ & $\begin{array}{l}\text { Rel/Ref, } \\
\text { untreated }\end{array}$ & $\begin{array}{c}\text { F } 15 \mathrm{mg} / \mathrm{m}^{2} \text { i.v. } \\
\text { D1-4, C } 250 \mathrm{mg} / \mathrm{m}^{2} \\
\text { i.v. D } 1-4, \\
\text { E } 60 \mathrm{mg} / \mathrm{m}^{2} \text { i.v. } \\
\text { D } 1 \mathrm{q} 28 \mathrm{~d}\end{array}$ & $81 / 36$ & $\begin{array}{c}\text { ANC gr. IV } \\
43 \%\end{array}$ & FUO $26 \%$ & 4 \\
\hline $\begin{array}{l}\text { Marotta, } \\
2000\end{array}$ & 20 & \begin{tabular}{|l|}
$75(61-87)$ \\
\end{tabular} & Rel/Ref & $\begin{array}{c}\text { F } 15 \mathrm{mg} / \mathrm{m}^{2} \text { i.v. } \\
\text { D1-4, C } 200 \mathrm{mg} / \mathrm{m}^{2} \\
\text { i.v. D1-4 q28d }\end{array}$ & $85 / 15$ & $\begin{array}{c}\text { ANC gr. IV } \\
20 \%\end{array}$ & $\begin{array}{l}\text { 1x infection } \\
\text { gr. IV, } \\
\text { 1x TLS }\end{array}$ & 36 \\
\hline $\begin{array}{l}\text { Fabbri, } \\
2004\end{array}$ & $28 * *$ & $73.5(61-85)$ & Rel/Ref & $\begin{array}{c}\text { F } 25 \mathrm{mg} / \mathrm{m}^{2} \text { p.o. } \\
\text { D1-4, C } 150 \mathrm{mg} / \mathrm{m}^{2} \\
\text { p.o. D } 1-4 \mathrm{q} 28 \mathrm{~d}\end{array}$ & $100 / 0$ & NS & 1x fatal sepsis & 20 \\
\hline $\begin{array}{l}\text { Fabbri, } \\
2007\end{array}$ & $25 * * *$ & \begin{tabular}{|l}
$74(66-85)$ \\
\end{tabular} & Untreated & $\begin{array}{c}\text { F } 25 \mathrm{mg} / \mathrm{m}^{2} \text { p.o. } \\
\text { D1-4, C } 150 \mathrm{mg} / \mathrm{m}^{2} \\
\text { p.o. D } 1-4 \mathrm{q} 28 \mathrm{~d}\end{array}$ & $88 / 50$ & $\begin{array}{l}\text { ANC gr. } \\
\text { III/IV } 16 \%\end{array}$ & $\begin{array}{c}3 \times \mathrm{xUO}, \\
\text { 1x pneumonia }\end{array}$ & 21 \\
\hline $\begin{array}{l}\text { Forconi, } \\
2008\end{array}$ & 14 & \begin{tabular}{|l}
$71(65-80)$ \\
\end{tabular} & Untreated & $\begin{array}{c}\text { F } 25 \mathrm{mg} / \mathrm{m}^{2} \text { p.o. } \\
\text { D1-4, C } 120 \mathrm{mg} / \mathrm{m}^{2} \\
\text { p.o. D } 1-4 \mathrm{q} 28 \mathrm{~d}\end{array}$ & $100 / 62$ & $\begin{array}{c}\text { ANC gr. } \\
\text { III/IV } 21 \%\end{array}$ & - & 28 \\
\hline $\begin{array}{l}\text { Forconi, } \\
2008\end{array}$ & 12 & \begin{tabular}{|l|}
$71(65-79)$ \\
\end{tabular} & Rel/Ref & $\begin{array}{l}\text { F } 25 \mathrm{mg} / \mathrm{m}^{2} \text { p.o. } \\
\text { D1-4, C } 120 \mathrm{mg} / \mathrm{m}^{2} \\
\text { p.o. D } 1-4 \mathrm{q} 28 \mathrm{~d}\end{array}$ & $84 / 25$ & $\begin{array}{c}\text { ANC gr. } \\
\text { III/IV } 25 \%\end{array}$ & $2 \mathrm{x}$ pneumonia & 28 \\
\hline
\end{tabular}

Rel/Ref - relapsed/refractory; F - fludarabine; C - cyclophosphamide; E - epirubicin; D - day; ANC - neutropenia; NS - not stated; FUO - fever of unknown origin; Ref - reference.

*patients with indolent lymphomas including 11 cases of SLL; **patients with indolent lymphomas including 4 cases of SLL; ***patients with indolent lymphomas including 8 cases of SLL. 
Significantly higher toxicity of full-dose fludarabine combinatis can be at least in part explained by slower excretion of fludarabine metabolites via kidneys as renal functions deteriorates with advanced age. To try to resolve this issue, dose-reduced fludarabine regimens were developed aiming at reduction of the treatment toxicity while maintaining efficacy. Indeed, several small studies have reported decent response rates and modest toxicity of either lowdose fludarabine monotherapy (49) or low-dose FC combination $(4,20,21,28,36)$. The results of these studies are summarized in Table 2. The logical next step is combination of low-dose chemotherapy with monoclonal antibodies. Protocol "FCR-Lite" consists of low-dose FC (fludarabine, $20 \mathrm{mg} / \mathrm{m}^{2}$ and cyclophosphamide $150 \mathrm{mg} / \mathrm{m}^{2}$ i.v. day $1-3$ of the cycle $)$ is and double dose of rituximab $\left(500 \mathrm{mg} / \mathrm{m}^{2}\right.$ day 1 and 14 of the cycle, repeated q 28 days); patients who achieve partial or complete response receive maintenance treatment with rituximab $500 \mathrm{mg} / \mathrm{m}^{2}$ every three months for 2 years. Preliminary results in a selected group of 49 untreated patients were impressive: ORR/CR was achieved in 100/85 \%; 7/8 patients in CR were MRD-negative. With regard to toxicity, the regimen was very well tolerated. Grade III/IV neutropenia occured in $12 \%$ of cycles only. Ironically, the patients were neither elderly nor comorbid: median age was 58 years, patients were predominantly in intermediate clinical stages and had excellent performance status (27); therefore, these results are not relevant for the elderly/comorbid CLL patient population. Efficacy and safety of low-dose FCR in elderly/comorbid patients is currently tested within protocol "Q-lite" of the Czech CLL Study Group (44). Preliminary results are pending this year. Combination of pentostatin $\left(2 \mathrm{mg} / \mathrm{m}^{2}\right)$, cyclophosphamide $\left(600 \mathrm{mg} / \mathrm{m}^{2}\right)$, and rituximab $\left(375 \mathrm{mg} / \mathrm{m}^{2}\right)$ was used in 64 previously untreated patients with CLL (50). Eighteen patients were older than 70 years and 25 had creatinine clearance below $70 \mathrm{ml} / \mathrm{min}$. These subgroups did not have significantly inferior results or higher occurence of cytopenia; howerver, older patients had more treatment delays and those with impaired renal function required more dose reductions; furthemore, the study was not statistically powered to test for these differences and direct comparison with fludarabine regimens was not available. Therefore, more data are needed to address the question whether pentostatine could be less toxic than fludarabine and thus more suitable for elderly/comorbid patients with CLL.

\section{Refractory CLL}

Management of patients with refractory CLL represents a truly challenging task for every hematologist (52). Monoclonal anti-CD52 antibody alemtuzumab is approved for use patients who have failed fludarabine-based regimens. ORR can be expected at 30-40\% but responses often last less than 12 months (8). Furthemore, opportunistic infections are frequent so benefits must be carefully weighed against the risks. Patients who are double refractory to fludarabine and alemtuzumab or those fludarabine-refractory with bulky lymphadenopathy (where alemtuzumab efficacy is less likely) have a particularly dismal prognosis (54). One of emerging treatment options for these patients is the use of high-dose corticosteroids. Combination of high-dose methylprednisolone (HDMP) at the dose of 1 $\mathrm{g} / \mathrm{m}^{2}$ i.v. day $1-5$ with rituximab $375 \mathrm{mg} / \mathrm{m}^{2}$ i.v. day 1 repeated every 4 weeks was used in 14 heavily pretreated patients, most of them with bulky lymphadenopathy, six being older than 65 years (14). ORR was $93 \%$ with 2 CRs. The problem, however, was short duration of response (median PFS, 7 months) and grave infectious toxicity despite combined prophylaxis: $6 / 14$ patients had a significant opportunistic infection while on treatment. The Mayo Clinic group treated 37 relapsed CLL patients with HDMP at the same dose in combination with weekly schedule of rituximab (day $1,8,15$ and 22). ORR was $78 \%$ and median PFS around 12 months. Again, infections were serious: five early deaths due to infection during the first month of treatment occured (5). Castro et al. treated 14 fludarabine-refractory patients by 3 cycles of R-HDMP at the same dose. ORR/CR were 93/36 \%; median PFS 15 months and median time to next treatment 22 months. Interestingly, serious adverse evets were rare (6). Solution of the common problem with infectious toxicity could lie in lowering the dose of steroids: use of high-dose dexamethasone ( $40 \mathrm{mg}$ on days $1-4$ repeated every 28 days) with rituximab was reported by Quinn; six patients treated with this regimen has similar results to those treated by HDMP but toxicity was notably lower with dexamethasone (45). Czech authors recently reported promising results of treatment of autoimmune cytopenias by rituximab with HDMP or dexamethasone (13). Ofatumumab, a fully human anti-CD20 antibody has recently been approved by FDA for the treatment of CLL patients double-refractory to fludarabine and alemtuzumab. The schedule used in the registration study was $1 \times 300 \mathrm{mg}$ $+7 \times 2000 \mathrm{mg}$ by intravenous infusions weekly followed by four monthly doses of $2000 \mathrm{mg}$. Results were promising given the highly unfavourable patient cohort: ORR was $51 \%$ in the double-refractory patients and $44 \%$ in the bulky fludarabine-refractory group. Median OS was 14 and 15 months (57).

\section{Future directions}

Combination of chlorambucil and monoclonal antibodies offers a promising way to increase the therapeutic efficacy while maintaining low toxicity. Protocol combining chlorambucil and rituximab, i.e. two agents with a very favourable toxicity profile and synergistic mode of action in vitro, is currently studied in the United Kingdom (ruximab, $500 \mathrm{mg} / \mathrm{m}^{2}$, in first cycle $375 \mathrm{mg} / \mathrm{m}^{2}$; chlorambucil, 10 $\mathrm{mg} / \mathrm{m}^{2}$ p.o. day $1-7$; repeated every 28 days). Preliminary results showed that ORR achieved with the combination in 50 patients was better than chlorambucil monotherapy in historical comparison to results of British CLL4 trial 
(ORR, 84 vs $67 \%$ ). Interestingly, grade III/IV neutropenia was relatively high at $40 \%$ (31). German CLL Study Group is enrolling patients into a large phase III trial randomizing between chlorambucil monotherapy, chlorambucil+rituximab and chlorambucil+GA-101, a class II anti-CD20 monoclonal antibody with improved antibody - dependent cytotoxicity and direct induction of cell death. Combination of chlorambucil with ofatumumab vs chlorambucil monotherapy is tested in another phase III trial (40). No results from these studies are available to date.

While rituximab monotherapy has limited efficacy in CLL, probably due to lower CD20 density and circulating CD20 (8), one of the potential ways to increase the therapeutic response is combination with granulocyte-macrophage colony-stimulating factor (GM-CSF) which has been shown to increase the CD20 expression on CLL cells. Combination of rituximab $\left(375 \mathrm{mg} / \mathrm{m}^{2}\right.$ i.v. weekly for 4 weeks) with GM-CSF ( $250 \mu \mathrm{g}$ s.c. $3 \mathrm{x}$ weekly for 8 weeks $)$ was studied as initial treatment in 32 patients with median age 73 years. ORR/CR rate was $72 / 6 \%$. Tolerability was excellent: no severe myelosuppression or infections were reported (24).

Bendamustin is a unique molecule combining the properties of an alkylating agent and a purine analog, originally developed in former German Democratic Republic in $1960 \mathrm{~s}$ and mainly used for the treatment of lymphomas. Bendamustine was approved by US Food and Drug Administration for the first-line treatment of CLL following demonstration of better ORR/CR and PFS in comparison to chlorambucil (33). German CLL Study Group published results of a dose escalation phase I/II study in 16 patients with relapsed/refractory CLL; median age was 67 years. The maximum tolerated dose was $70 \mathrm{mg} / \mathrm{m}^{2}$ i.v. on day 1 and 2, repeated every 4 weeks. ORR/CR was $56 / 13 \%$. The median duration of response was 43 months. Most frequent grade III/IV toxicities included leukopenia (50\%) and infections (44\%) (3). The next logical step, combination of bendamustine with rituximab, was reported by the same group in 81 patients (median age 67 years) with relapsed/refractory CLL. The regimen yielded ORR/CR of $77 / 15 \%$. Severe neutropenia and thrombocytopenia occured in 12 and $9 \%$ of treatment courses and there were $5 \%$ severe infections. Treatment-related mortality was $4 \%$ ( 3 patients $2 \mathrm{x}$ sepsis, 1x pneumonia) (25). These results suggest that bendamustine might be an effective and above all safe drug for the treatment of elderly CLL patients.

Lenalidomide, an orally available immunomodulatory drug which targets the interactions of leukemic cells with the bone marrow and lymph node microenvironment, was tested in a phase II study as initial treatment in 43 elderly CLL patients (median age, 72 years; $42 \%$ in Rai III/IV stage). The drug was given continuously at a starting dose of $5 \mathrm{mg}$ with possible escalation after 8 weeks. ORR was $54 \%$ with no CRs. The median daily dose administered was $10 \mathrm{mg}$. Toxicity was acceptable: severe neutropenia and/or thrombocytopenia developed in $26 \%$. Infections ( $2 \mathrm{x}$ neu- tropenic fever, 1x pneumonia) Tumor flare ocurred in (44 \%) but was limited to grade I/II. Importantly, no tumor lysis syndrome was seen (23).

\section{Practical points in the management of elderly/comorbid patients with CLL}

\section{Diagnosis of CLL}

It is perfectly fine to use peripheral blood for confirmation of the diagnosis by flow cytometry and there is usually no need in performing bone marrow aspiration/biopsy as part of initial staging. This procedure, giving its demands for the patient, should be reserved for those presenting with cytopenias where marrow cytology and/or histology may provide clues to etiology of the cytopenia (29).

\section{Extent of staging}

Besides basic laboratory tests such as full blood count, biochemistry, and antiglobulin test, I usually order abdominal ultrasonography to detect possible retroperitoneal lymphadenopathy. In my experience, a significant proportion of patients have enlarged abdominal lymph nodes and some of them may progress in retroperitoneal lymph nodes only while their external lymph nodes remain stable. Patients with relapsed CLL have even more frequently significant abdominal lymphadenopathy. In these patients, assessment of the largest lymph nodes is even more important if we consider using alemtuzumab because this agent is considerably less effective in patients with bulky lymphadenopathy (8). Prognostic relevance of imaging methods in CLL $(38,41)$ as well as small lymphocytic lymphoma (53) has been reported.

\section{Treatment decisions}

Before initiating treatment, the most important question is, whether the patient is truly indicated for therapy. We must keep in mind that every therapeutic intervention may result in potentially severe side effects. Therefore, the "primum non nocere" (first do no harm) principle is highly relevant. I follow the NCI-WG criteria for the commencement of treatment - these guidelines are based on disease activity, e.g. massive or progressive lymphadenopathy or splenomegaly, progressive anemia and/or thrombocytopenia, systemic symptoms (significant weight loss, non-infectious fevers, fatigue or night sweats) or rapid lymphocyte doubling time (less than 6 months). However, in specific cases, the treatment does not necessarily have to be initiated even though one of the criteria is fullfilled: in patients with mild thrombocytopenia above $70 \times 10^{9} / 1$, it pays to monitor the patient's blood count closely because in some patients the platelets (though mildly decreased) may remain stable for a longer period of time. I also recommend patience with regard to lymphocyte doubling time. Obviously, some patients quickly double the absolute lymphocyte count (ALC) from 30,000 to $60,000 / \mathrm{mm}^{3}$. Given that ALC itself is not harmful to the patient, I usually continue with close follow- 
up (every 6-8 weeks) and wait for the further development of blood count. In many patients the rise in leukocytes will slow down, following the gompertzian curve of tumor growth. If the patient definitely requires treatment, it is extremely important to thoroughly discuss treatment possibilities with the patient in order to choose the type of treatment that best suits and fits the patient (not necessarily the physician!). As every patient is different and there are often several good options instead of "the only good one", it is crucial to respect the patient's preferences and fully explain the pros and cons of all reasonable therapeutic options.

It is advantageous if a patient can be offered one of the currently active clinical studies testing novel (and expectedly more effective) therapies in CLL, such as lenalidomide, chlorambucil-monoclonal antibody combination, ABT-263 (an orally available bcl-2 inhibitor) or maintenance treatment - see Table 3. Importantly, patients with small lymphocytic lymphoma (SLL) should be managed in the same way as SLL differs from CLL in tumor distribution only (53).

\section{Choice of specific treatment regimen}

With regard to intensity of treatment, it is crucial to assess the patient's fitness general condition and adjust the extent of diagnostic procedures and therapeutical goals accordingly. It is better to use biological age rather than calendar age as there may be huge differences between different patients of the same age. While Eastern Cooperative Oncology Group (ECOG) performance status is a suitable basic tool, it does not tell us anything about the number and severity of comorbid diseases. Regarding assessment of comorbidities, I follow the practice of German CLL Study Group which uses Cumulative Illness Rating Scale (CIRS) system in its studies (29). This system scores number and severity of comorbidities in each of the organ system and its predictive power has been shown in patients with solid tumors (19). Threshold of 6 was used in German studies to distinguish between significantly comorbid patients and those without serious comorbidities. Patients aged 65-70 (sometimes 75) in good general condition, with perfor- mance status $0-1$, CIRS score $\leq 6$ creatinine clearance $\geq 70$ $\mathrm{ml} / \mathrm{min}$. and no serious comorbidity (such as advanced cardiac failure or ischemic heart disease) usually receive the same treatment regimens as younger patients, e.g. full-dose FCR, alemtuzumab etc.

\section{Supportive treatment}

While infections are clearly the predominant complications and the most common cause of death in CLL patients, it is essential to try to maximize the patients' protection from infections, especially during cytoreductive treatment. While the rate of infectious complications is relatively low in younger patients undergoing first-line therapy (16), occurence of infections seems to rapidly increase with every subsequent line; patients refractory to fludarabine and/or alemtuzumab are in particular susceptible to various opportunistic infections (54). My personal practice is to offer combined antimicrobial prophylaxis to all elderly patients undergoing treatment based on fludarabine or corticosteroids. The prophylactic regimen usually consists of sulphametoxazol/trimetoprim $960 \mathrm{mg}$ twice daily on three days of the week (Monday, Wednesday, Friday) combined with an antiviral agent such as aciclovir $400 \mathrm{mg}$ or valaciclovir 500 $\mathrm{mg}$ twice daily. Antimycotic prophylaxis is usually reserved to patients with a history of repeated or severe mycotic infections. The prophylaxis is maintained until at least 2 months after cessation of chemotherapy. This prophylaxis is absolutely mandatory in patients treated with alemtuzumab. Patients presenting with high tumor load (massive lymphadenopathy/splenomegaly, hyperleukocytosis) receive allopurinol at the dose of 300-600 mg daily as the prophylaxis of tumor lysis syndrome; adequate hydration is also crucial. Regarding growth factor support, I rarely use primary prophylaxis of febrile neutropenia with granulocyte colony-stimulating factor (G-CSF); instead, this agent is used in case of severe neutropenia and I usually reduce the doses of chemotherapy by $25 \%$ in the subsequent cycles. Erythropoiesis-stimulating agents (ESP) are used in concordance to international guidelines (ESMO, NCCN, EORTC). Intravenous immunoglobulins are usually administered to patients with severe hypogammaglobulinemia and history

Tab. 3: Current clinical trials suitable for elderly/comorbid patiens with CLL. CLB, chlorambucil; FCR, fludarabine, cyclophosphamide, rituximab.

\begin{tabular}{|l|l|l|l|l|}
\hline Drug/regimen & Mechanism of action & Patient population & Design of study & Manufacturer \\
\hline ABT-263 & Bcl-2 inhibitor & Untreated & Rituximab vs. rituximab + ABT-263 & Genentech \\
\hline GA-101 & $\begin{array}{l}\text { Class II anti-CD20 } \\
\text { monoclonal antibody }\end{array}$ & Untreated & $\begin{array}{l}\text { CLB vs. CLB + rituximab } \\
\text { vs. CLB + GA-101 }\end{array}$ & Roche \\
\hline Ofatumumab & $\begin{array}{l}\text { Human anti-CD20 } \\
\text { monoclonal antibody }\end{array}$ & Untreated & CLB vs. CLB + ofatumumab & GlaxoSmithKline \\
\hline Rituximab & $\begin{array}{l}\text { Anti-CD20 } \\
\text { monoclonal antibody }\end{array}$ & Untreated & $\begin{array}{l}\text { CLB vs. CLB + rituximab } \\
\text { vs. CLB + GA-101 }\end{array}$ & Roche \\
\hline Lenalidomide & $\begin{array}{l}\text { Targeting tumor } \\
\text { microenvironment }\end{array}$ & Untreated & CLB vs. lenalidomide & Celgene \\
\hline Low-dose FCR & Chemoimmunotherapy & Untreated/relapse & Low-dose FCR (single arm) & Roche, Genzyme \\
\hline
\end{tabular}


of repeated severe bacterial infections, though there have been no convincing data from randomized trials.

\section{Conclusions}

Treatment of elderly or comorbid patients with CLL represents a challenging task. The lack of data from randomized trials make the treatment decisions difficult. As there is yet no evidence of any regimen being better than chlorambucil in this patient population, it is still the standard treatment in first line. While best supportive care appears to be the best option in severely comorbid patients, others with moderate comorbidities may profit from chlorambucil cominations or other approaches. Comprehensive geriatric assessment (such as CIRS) offers a useful tool to distinguish between these categories. Quantification of creatinine clearance is also important, especially if planned treatment includes fludarabine. It is highly advantageous to enroll as many elderly/comorbid patients into currently running randomized trials testing combination of chlorambucil+rituximab, chlorambucil+ofatumumab or chlorambucil+GA-101, monotherapy with rituximab or lenalidomide and others (NCI, see Table 3). Low-dose fludarabine combinations have yielded promising results in small phase II studies which should be confirmed in larger trials. In refractory CLL, treatment options include alemtuzumab, ofatumumab and high-dose corticosteroids. Supportive treatment with antimicrobial prophylaxis is crucial. With many clinical trials currently under way, we can hope that our treatment options aiming at the ultimate therapeutic goals in CLL patients of advanced age or with comorbidities - prolongation of overall survival and improvement in quality of life - will be improved in near future.

\section{Acknowledgements and conflict of interest statement}

The author has received honoraria and/or travel grants from Roche, Bayer-Schering Pharma, Genzyme and GlaxoSmithKline. This work was supported by research project MZO 00179906 from Ministry of Health, Czech Republic.

\section{References}

1. Abrisqueta P, Pereira A, Rozman C, Aymerich M, Gine E, Moreno C, et al Improving survival in patients with chronic lymphocytic leukemia (1980-2008): the Hospital Clinic of Barcelona experience. Blood. 2009; 114(10): 2044-50.

2. Altman SJ, Haut A, Cartwright GE, Wintrobe MM. Early experience with $\mathrm{p}$ (N,N-di-2-chloroethyl)-aminophenylbutyric acid (CB 1348), a new chemotherapeutic agent effective in the treatment of chronic lymphocytic leukemia. Cancer. 1956; 9(3): 512-7.

3. Bergmann MA, Goebeler ME, Herold M, Emmerich B, Wilhelm M, Ruelfs C, et al. Efficacy of bendamustine in patients with relapsed or refractory chronic lymphocytic leukemia: results of a phase I/II study of the German CLL Study Group. Haematologica. 2005; 90(10): 1357-64.

4. Bocchia M, Bigazzi C, Marconcini S et al. Favorable impact of low-dose fludarabine plus epirubicin and cyclophosphamide regimen (FLEC) as treatment for low-grade non-Hodgkin's lymphomas. Haematologica. 1999; 84(8): 716-20.

5. Bowen DA, Call TG, Jenkins GD et al. Methylprednisolone-rituximab is an effective salvage therapy for patients with relapsed chronic lymphocytic leukemia including those with unfavorable cytogenetic features. Leuk Lymphoma. 2007; 48(12): 2412-7.
6. Castro JE, Sandoval-Sus JD, Bole J et al. Rituximab in combination with highdose methylprednisolone for the treatment of fludarabine refractory high-risk chronic lymphocytic leukemia. Leukemia. 2008; 22(11): 2048-53.

7. Catovsky D, Richards S, Matutes E, Oscier D, Dyer MJ, Bezares RF, et al. Assessment of fludarabine plus cyclophosphamide for patients with chronic lymphocytic leukaemia (the LRF CLL4 Trial): a randomised controlled trial. Lancet. 2007; 370(9583): 230-9.

8. Cheson BD. Monoclonal antibody therapy of chronic lymphocytic leukemia. Cancer Immunol Immunother. 2006; 55(2): 188-96.

9. Cockcroft DW, Gault MH. Prediction of creatinine clearance from serum creatinine. Nephron. 1976; 16(1): 31-41.

10. Cramer P, Goede V, Jenke $P$ et al. Impact of different chemotherapy regimen in comorbid patients with advanced chronic lymphocytic leukemia: metaanalysis of two phase-III-trials of the German CLL study group. Blood 2006; 108.

11. Diehl LF, Karnell LH, Menck HR. The American College of Surgeons Commission on Cancer and the American Cancer Society. The National Cancer Data Base report on age, gender, treatment, and outcomes of patients with chronic lymphocytic leukemia. Cancer. 1999; 86(12): 2684-92.

12. Dores GM, Anderson WF, Curtis RE, Landgren O, Ostroumova E, Bluhm EC, et al. Chronic lymphocytic leukaemia and small lymphocytic lymphoma: overview of the descriptive epidemiology. Br J Haematol. 2007; 139(5): 809-19.

13. Doubek M, Smolej L, Panovksa A, Brychtova Y, Mayer J. Rituximab in combination with dexamethasone or high-dose methylprednisolone in refractory chronic lymphocytic leukemia. XIII International Workshop on Chronic Lymphocytic Leukemia; Spain, 16-18 October 2009. Haematologica 2009; 94(s3): abstract 7.3

14. Dungarwalla M, Evans SO, Riley U et al. High dose methylprednisolone and rituximab is an effective therapy in advanced refractory chronic lymphocytic leukemia resistant to fludarabine therapy. Haematologica. 2008; 93(3): 475-6.

15. Eichhorst BF, Busch R, Hopfinger G, Pasold R, Hensel M, Steinbrecher C, et al Fludarabine plus cyclophosphamide versus fludarabine alone in first-line therapy of younger patients with chronic lymphocytic leukemia. Blood. 2006; 107(3): 885-91.

16. Eichhorst BF, Busch R, Schweighofer C, Wendtner CM, Emmerich B, Hallek M Due to low infection rates no routine anti-infective prophylaxis is required in younger patients with chronic lymphocytic leukaemia during fludarabine-based first line therapy. Br J Haematol. 2007; 136(1): 63-72.

17. Eichhorst BF, Busch R, Stilgenbauer S, Stauch M, Bergmann MA, Ritgen M, et al. First-line therapy with fludarabine compared with chlorambucil does not result in a major benefit for elderly patients with advanced chronic lymphocytic leukemia. Blood. 2009; 114(16): 3382-91.

18. Eichhorst B, Goede V, Hallek M. Treatment of elderly patients with chronic lymphocytic leukemia. Leuk Lymphoma. 2009; 50(2): 171-8.

19. Extermann M, Overcash J, Lyman GH, Parr J, Balducci L. Comorbidity and functional status are independent in older cancer patients. J Clin Oncol 1998; 16 : 1582-1587.

20. Fabbri A, Lenoci M, Gozzetti A, Marotta G, Raspadori D, Forconi F, et al. Lowdose oral fludarabine plus cyclophosphamide in elderly patients with chronic lymphoproliferative disorders. Hematol J. 2004; 5(6): 472-4.

21. Fabbri A, Lenoci M, Gozzetti A, Chitarrelli I, Olcese F, Raspadori D, et al. Lowdose oral fludarabine plus cyclophosphamide as first-line treatment in elderly patients with indolent non-Hodgkin lymphoma. Br J Haematol. 2007; 139(1): 90-3.

22. Ferrajoli A, O'Brien S, Wierda W et al. Treatment of patients with CLL 70 years old and older: a single center experience of 142 patients. Leuk Lymphoma 2005; 46(Suppl 1): S86 (abstract P95).

23. Ferrajoli A, O'Brien S, Wierda W et al. Lenalidomide as initial treatment of elderly patients with chronic lymphocytic leukemia (CLL). Blood (ASH Annual Meeting Abstracts) 2008; 112: 23 (abstract 45).

24. Ferrajoli A, O’Brien S, Faderl S, Wierda W, Jorgensen J, Keating MJ. The combination of rituximab and GM-CSF as frontline treatment for elderly patients with chronic lymphocytic leukemia. Leuk Lymphoma 2007; 48(Suppl 1): S161 (abstract P 5.03)

25. Fischer K, Stilgenbauer S, Schweighofer CD et al. Bendamustine in Combination with Rituximab (BR) for Patients with Relapsed Chronic Lymphocytic Leukemia (CLL): A Multicentre Phase II Trial of the German CLL Study Group (GCLLSG). Blood (ASH Annual Meeting Abstracts) 2008; 112: Abstract 330.

26. Flinn IW, Neuberg DS, Grever MR, Dewald GW, Bennett JM, Paietta EM, et al. Phase III trial of fludarabine plus cyclophosphamide compared with fludarabine for patients with previously untreated chronic lymphocytic leukemia: US Intergroup Trial E2997. J Clin Oncol. 2007; 25(7): 793-8.

27. Foon KA, Boyiadzis M, Land SR et al. Chemoimmunotherapy with low-dose fludarabine and cyclophosphamide and high dose rituximab in previously untreated patients with chronic lymphocytic leukemia. J Clin Oncol. 2009; 27(4): 498-503.

28. Forconi F, Fabbri A, Lenoci M, Sozzi E, Gozzetti A, Tassi M, et al. Low-dose oral fludarabine plus cyclophosphamide in elderly patients with untreated and relapsed or refractory chronic lymphocytic Leukaemia. Hematol Oncol. 2008; 26(4): 247-51.

29. Hallek M, Cheson BD, Catovsky D, et al. Guidelines for the diagnosis and treatment of chronic lymphocytic leukemia: a report from the International Workshop 
on Chronic Lymphocytic leukemia updating the National Cancer InstituteWorking Group 1996 guidelines. Blood. 2008; 111(12): 5446-5456.

30. Hallek M, Fingerle-Rowson G, Fink AM et al. First-Line Treatment with Fludarabine (F), Cyclophosphamide (C), and Rituximab (R) (FCR) Improve Overall Survival (OS) in Previously Untreated Patients (pts) with Advanced Chronic Lymphocytic Leukemia (CLL): Results of a Randomized Phase III Trial On Behalf of An International Group of Investigators and the German CLL Study Group. Blood (ASH Annual Meeting Abstracts) 2009; 114: Abstract 535 .

31. Hillmen P, Gribben JG, Follows GA et al. An Open-Label Phase II Study to Investigate the Safety and Efficacy of Rituximab Plus Chlorambucil in Previously Untreated Patients with CD20-Positive B-Cell Chronic Lymphocytic Leukaemia (CLL). Blood (ASH Annual Meeting Abstracts) 2009; 114: abstract 3428.

32. Janssen-Heijnen ML, van Spronsen DJ, Lemmens VE et al. A population-base study of severity of comorbidity among patients with non-Hodgkin's lymphoma: prognostic impact independent of International prognostic index. Br J Haemato 2005; 129: 597-606.

33. Knauf WU, Lissichkov T, Aldaoud A, Liberati A, Loscertales J, Herbrecht R, et al. Phase III randomized study of bendamustine compared with chlorambucil in previously untreated patients with chronic lymphocytic leukemia. J Clin Oncol. 2009; 27(26): 4378-84

34. Lindeman RD. Changes in renal function with aging. Implications for treatment Drugs Aging. 1992; 2(5): 423-31

35. Linet MS, Schubauer-Berigan MK, Weisenburger DD, Richardson DB, Landgren $\mathrm{O}$, Blair A, et al. Chronic lymphocytic leukaemia: an overview of aetiology in light of recent developments in classification and pathogenesis. Br J Haematol. 2007; 139(5): 672-86

36. Marotta G, Bigazzi C, Lenoci M, Tozzi M, Bocchia M, Lauria F. Low-dose fludarabine and cyclophosphamide in elderly patients with B-cell chronic lymphocytic leukemia refractory to conventional therapy. Haematologica. 2000; 85(12): 1268-70.

37. Martell RE, Peterson BL, Cohen HJ, Petros WP, Rai KR, Morrison VA, et al Analysis of age, estimated creatinine clearance and pretreatment hematologic parameters as predictors of fludarabine toxicity in patients treated for chronic lymphocytic leukemia: a CALGB (9011) coordinated intergroup study. Cance Chemother Pharmacol. 2002; 50(1): 37-45.

38. Muntanola A, Bosch F, Arguis P, Arellano-Rodrigo E, Ayuso C, Gine E, et al. Abdominal computed tomography predicts progression in patients with Rai stage 0 chronic lymphocytic leukemia. J Clin Oncol. 2007; 25(12): 1576-80.

39. National Cancer Institute: SEER Cancer Statistics Review. Available at http://seer.cancer.gov. Accessed on 10.2.2010.

40. National Cancer Institute: Registry of clinical trials. Available at http://www.cancer.gov/clinicaltrials/search. Accessed on 28.3.2010.

41. Norin S, Kimby E, Lundin J. Tumor burden status evaluated by computed tomography scan is of prognostic importance in patients with chronic lymphocytic leukemia. Med Oncol. 2009 (online early)

42. Piccirillo JF, Tierney RM, Costas I, Grove L, Spitznagel EL Jr. Prognostic importance of comorbidity in a hospital-based cancer registry. JAMA 2004; 291 $2441-2447$.
43. Plunkett W, Gandhi V, Huang P, Robertson LE, Yang LY, Gregoire V, et al. Fludarabine: pharmacokinetics, mechanisms of action, and rationales for combination therapies. Semin Oncol. 1993; 20(5 Suppl 7): 2-12.

44. Protocol Q-lite of Czech CLL Study Group. Available online at http:// www.cll.cz/studie-granty-projekty/. Accessed on 8.2.2010.

45. Quinn J, Sajir M, Chipperfield K et al. Efficacy of rituximab in combination with steroids in refractory chronic lymphocytic leukaemia. Leuk Lymphoma 2008; 49 : 1995-1998

46. Rai KR, Peterson BL, Appelbaum FR, Kolitz J, Elias L, Shepherd L, et al. Fludarabine compared with chlorambucil as primary therapy for chronic lymphocytic leukemia. N Engl J Med. 2000; 343(24): 1750-7.

47. Robak T, Dmoszynska A, Solal-Celigny P, Warzocha K, Loscertales J, Catalano $\mathrm{J}$, et al. Rituximab Plus Fludarabine and Cyclophosphamide Prolongs Progression-Free Survival Compared With Fludarabine and Cyclophosphamide Alone in Previously Treated Chronic Lymphocytic Leukemia. J Clin Oncol. 2010 ePub online.

48. Robak T, Jamroziak K, Gora-Tybor J, Stella-Holowiecka B, Konopka L, Ceglarek B, et al. Comparison of Cladribine Plus Cyclophosphamide With Fludarabine Plus Cyclophosphamide As First-Line Therapy for Chronic Lymphocytic Leukemia: A Phase III Randomized Study by the Polish Adult Leukemia Group (PALG-CLL3 Study). J Clin Oncol. 2010, ePub online.

49. Robertson LE, O’Brien S, Kantarjian H, Koller C, Beran M, Andreeff M, et al A 3-day schedule of fludarabine in previously treated chronic lymphocytic leukemia. Leukemia. 1995; 9(9): 1444-9.

50. Shanafelt TD, Lin T, Geyer SM, Zent CS, Leung N, Kabat B, et al. Pentostatin, cyclophosphamide, and rituximab regimen in older patients with chronic lymphocytic leukemia. Cancer 2007; 109: 2291-2298.

51. Shvidel L, Shtalrid M, Bairey O et al; Israeli Study Group on CLL. Conventiona dose fludarabine-based regimens are effective but have excessive toxicity in elderly patients with refractory chronic lymphocytic leukemia. Leuk Lymphoma. 2003; 44(11): 1947-50.

52. Smolej L. Modern concepts in the treatment of chronic lymphocytic leukemia. Hematology. 2009; 14(5): 249-54

53. Smolej L, Vasova I, Salkova J, et al. Small Lymphocytic Lymphoma (SLL) Retrospective Analysis From the Registry of Czech Lymphoma Study Group. Haematologica 2009; 94 (Suppl 3): S5 (abstract 1.11).

54. Tam CS, O’Brien S, Lerner S, Khouri I, Ferrajoli A, Faderl S, et al. The natura history of fludarabine-refractory chronic lymphocytic leukemia patients who fail alemtuzumab or have bulky lymphadenopathy. Leuk Lymphoma. 2007; 48(10): $1931-9$.

55. Thurmes P, Call T, Slager S, Zent C, Jenkins G, Schwager S, et al. Comorbid conditions and survival in unselected, newly diagnosed patients with chronic lymphocytic leukemia. Leuk Lymphoma. 2008; 49(1): 49-56.

56. Wierda WG, O'Brien S, Wang X, Faderl S, Ferrajoli A, Do KA, et al. Characteristics associated with important clinical end points in patients with chronic lymphocytic leukemia at initial treatment. J Clin Oncol. 2009; 27(10): 1637-43.

57. Wierda WG, Kipps TJ, Mayer J, Stilgenbauer S, Williams CD, Hellmann A, et al. Ofatumumab As Single-Agent CD20 Immunotherapy in Fludarabine-Refractory Chronic Lymphocytic Leukemia. J Clin Oncol. 2010 (online early).

Received: $01 / 04 / 2010$.

Accepted in revised form: 20/09/2010.

\section{Corresponding author:}

Lukáš Smolej, M.D., Ph.D., $2^{\text {nd }}$ Department of Medicine, Department of Hematology, University Hospital and Medical School, Sokolská 581, 50005 Hradec Králové, Czech Republic; e-mail: smolej@seznam.cz 